\title{
Psychological Status Analysis and Moral Education Strategy Research of Vocational College Students in the Post-epidemic Era
}

\author{
Yurong Cheng, Jian Zhang \\ Chongqing Education Management School, Chongqing 401320, China \\ Email: 307242919@qq.com
}

\begin{abstract}
Due to the impact of COVID-19 's epidemic on education, the psychological problems of vocational college students have become more prominent. The main manifestations are tension in interpersonal relationships, low self-esteem, isolation, learning disabilities, improper communication between men and women, emotional instability, etc., prone to depression, anxiety, and tantrum. As for the causes of these psychological problems, they are related to family, social, school, and students themselves. The author puts forward a series of moral education strategies for the current situation of students, such as the integration of strong strengths between home and school, and concerted efforts to maintain health, channels for communication between teachers and students, bridges for spiritual communication, psychological education into the classroom, activities leading to effectiveness and other strategies, which are effective to solve students' psychological problems and promote their healthy development.
\end{abstract}

Keywords: post-epidemic era, vocational college students, psychological status, moral education strategy

At the beginning of 2020, COVID-19 epidemic is raging and constitutes a global public health event, which has a great impact on society, education and other aspects. Facing more than three months of online teaching, schools, teachers, and students responded hastily and were unprepared. How can they carry out online learning? How can they improve learning efficiency? What should be done in practice? In addition, in the post-epidemic era, with the economic transformation and the advent of artificial intelligence era, jobs will be reduced, and a large number of labor in traditional industries will be replaced by intelligent robots. Therefore, students in secondary vocational schools are facing employment pressure and professional skills transformation. With the increasingly fierce social competition, the psychological pressure of secondary vocational students is also increasing, and the moral education of secondary vocational schools is facing new challenges.

\section{Analysis of the psychological status of vocational college students in the post- epidemic era}

Most of the students in vocational colleges come from rural areas, among which there are a considerable number of left-behind children. As students who failed in the college entrance examination, in addition to poor grades, they also have real problems such as poor study habits, lack of self-confidence, and lack of motivation. Due to the impact of the epidemic, online teaching was carried out for more than two months in 2020. After returning to school, students have various psychological problems, which are mainly manifested in the following aspects.

\subsection{Interpersonal problems}

The school is a bridge between students and society, and handling interpersonal relationships is very important for students to enter society. Contemporary college students are very eager to interact with others, form their own social circle, and be recognized by everyone. However, because some students grew up in a closed environment and developed autism, they are afraid of contact with people, afraid of interacting with people, and reluctant to participate in collective life. Over time, they will suffer from interpersonal communication difficulties and even psychological deformities. The contradiction between the complexity of interpersonal relationships and the simplicity of students' psychology makes students often frustrated in interpersonal communication. Some students are self-centered, selfish, arrogant, arrogant, narrow-minded, lack tolerance, and are often unpopular in a collective environment. Ma Jiajue is one of the most typical representatives. Poor interpersonal relationships can lead to lack of communication, psychological tension, and emotional depression, and make students feel lonely and frustrated that they cannot be dispatched, which seriously affects students' normal study and life. 


\subsection{Emotional problems}

Vocational school students are in their adolescence. Due to their relatively shallow social experience and insufficient social experience, coupled with their low self-control and self-regulation abilities, they have greater mood swings. They are not only susceptible to the interference and influence of various external factors, but also easy to be emotional, regardless of the consequences, and even cause some psychological contradictions and problems.

In addition, the student period is called the golden season of love, and the number of students in love is increasing. Early love is the easiest to make people impulsive, but also the easiest to cause pain. The adolescent education received by Chinese students is insufficient, the understanding of love and sex is insufficient, and the psychological preparation for sexual maturity is lacking. Their mystery, fear, and desire for the opposite sex are intertwined, which creates various psychological problems. Some students are troubled and anxious due to improper handling of love issues, serious depression and obstacles caused by loss of love, and even self-mutilation, suicide, or hurting others, which directly affects campus harmony. During the epidemic, students were closed at home for so long, and many students' emotional problems were also exposed. There has been a marked increase in misconduct between men and women on campus, and incidents of solving problems through violence are also increasing.

\subsection{Learning and employment barriers}

Employment is an important turning point in a student's life journey. The phenomenon of unemployed students after graduation is gradually increasing. Coupled with the impact of the epidemic this year, the employment of graduates has become a common problem, and finding an ideal job is even more difficult. Under this pressure, many students have feelings of depression, hesitation, and anxiety due to concerns about the future and the future, which naturally affect their study and life. If students do not handle well when choosing a job, they will often have unhealthy psychology, such as arrogance, low self-esteem, conformity, dependence, and comparison. After students experience all kinds of hardships, they are too stressed and may vent it through illegal channels such as alcohol abuse and fighting. These have a great influence on the formation of students' healthy personality.

\section{Analysis of the causes of students' psychological problems in the post-epidemic era}

Why do vocational school students have such a big psychological contrast after returning to school? Let's first analyze the reasons for the psychological problems of vocational students, and then seek relevant education strategies to effectively solve the problems.

\subsection{Family reasons}

There are two aspects of family factors that affect students' psychological development. One is genetic influence. Factors that are significantly affected by genetics include temperament, gender differences and multiple intelligence factors. The other is the parenting style of the family. The parenting style can be summarized into two dimensions, one is the parents' emotional attitude towards their children, and the other is the parents' requirements and control of their children. In a family with a democratic atmosphere, children will develop a cooperative, independent, and docile character. On the contrary, children will have problems such as negativity, resistance, indifference, and dependence. Due to the impact of the epidemic, many families have experienced unprecedented difficulties, including economics, study, and work. The emotional changes of parents have a direct impact on students' emotions.

\subsection{Social reasons}

In modern society, mass media is ubiquitous, and it plays a subtle and important role in shaping students' personality, social cognition, and emotional training. Nowadays, all kinds of negative and corrupt phenomena in society have a greater impact on students. These phenomena have generally magnified the dark side of society. For example, the view that "a good study is worse than a good life" makes many students very confused and confused. The decadent and declining ideas in society eroded students more seriously. Hedonism and utilitarianism overwhelm the ideals and beliefs of weakwilled people, leading to their lack of faith and selfishness and indifference. Coupled with the increasingly fierce social competition, the contradiction between ideals and reality, employment and future concerns are intertwined. Under tremendous pressure, the mental health of students is showing a deteriorating trend. With the spread of the global epidemic, the global economy has been hit unprecedentedly, and social instability has increased, which has also had a certain impact on the psychological conditions of vocational school students. 


\subsection{School reasons}

At present, many vocational colleges unilaterally emphasize knowledge education and professional education but neglect to cultivate students' comprehensive quality, especially psychological education and counseling, which makes students' psychological obstacles and problems unable to be solved, and they accumulate. Coupled with the impact of unhealthy campus culture, such as mobile phone addiction, obsessive "online games", online dating, etc., will cause students to waste their studies. Many students become decadent, do not want to make progress, and develop psychological problems. The utilitarian and administrative problems of school management will increase the psychological burden of students, and easily lead to psychological problems such as weak self-management ability and weak will.

\subsection{Personal reasons}

From the perspective of human development stage, vocational college students are in the developmental mature stage of self-acceptance, adapting to the society, interpersonal relationship, heterosexual communication, social responsibility and other events. They will inevitably suffer from emotional instability, psychological conflicts and other psychological problems due to their mental immaturity. From the perspective of the students' own characteristics, it is inevitable that students will find it difficult to deal with difficulties and setbacks. In addition, weak psychological quality and personality defects are individual factors that cause students' psychological problems.

\section{Moral education management strategies in the post-epidemic era}

In order to change the mental health status of vocational college students, improve the quality of moral education management in vocational colleges, and serve the growth and success of students, we apply the knowledge of psychology to management, link theory with practice, and form a set of effective measures.

\subsection{Home and school are integrated to form strong forces and work together to maintain students' health}

China's education is in a single-handed situation at a certain level. Parents send their students to school and leave them alone, either thinking that the education of the students is a matter of the school, or thinking that the parents are unable to manage the children. And society is a big stove, and students need to experience in this big stove, and sometimes they even face disastrous defeat. Therefore, society and the country should assume more responsibilities, such as setting up special parent schools or parent classrooms to strengthen the education of parents. Every family educates their children well, and society will be much more harmonious. Schools can also invite parents and professionals in the community to participate in the school's moral education management. For example, psychological counseling can be provided to students, and students can enter the community for experience. By inviting in and going out, the family, school, and society form a threein-one education pattern.

\subsection{There are channels for teacher-student communication, and spiritual communication is a bridge}

Teachers should actively pay attention to students' psychological problems, strengthen their life education, help them establish a correct outlook on life and values, and strengthen their education and guidance in moral education. Teachers must be role models for students. A group of students with psychological problems must have a teacher with psychological problems behind them. Therefore, teachers must be sunny and self-confident, must provide positive psychological hints to students, be their life mentors, and help students find the true meaning of getting along with their parents, classmates, teachers, and friends. At the same time, a mental health assistance mechanism can be established, through which party members can contact students to provide "one-to-one" and "point-to-point" assistance, and build a bridge of spiritual communication between students and teachers.

\subsection{Psychological education enters the classroom, activities lead to results}

Schools should bring mental health education into the classroom, so that there are weekly courses and monthly lectures. The school should also set up professional mental health training rooms, emotional venting rooms, etc., and arrange for special personnel to monitor and file mental health problems of students, and manage and regulate students with mental health problems. Schools should offer career planning courses to help students make career planning. Schools can use psychological questionnaires or measurement tools to help students understand their physical and mental qualities and professional inclination, and help students understand relevant professional information through visits, internships, lectures, and publicity, so that they can establish correct professional ideals and professional responsibility. Schools should 
guide students to correctly deal with setbacks in career choices, so that students can adopt reasonable methods to adjust their mentality, analyze the causes of failure, learn from failures, readjust their personal job search goals, and strive for new opportunities with confidence.

\section{References}

[1] Gong Chenyu. The painful period in the post-epidemic era requires more attention [N]. The Procuratorate Daily. 2020 (03): 04.

[2] Ministry of Education. Opinions of the Ministry of Education on Comprehensively Deepening Curriculum Reform and Implementing the Fundamental Task of Lide Shuren. Available from: http://old.moe.gov.cn/publicfiles/business/ htmlfiles/moe/s7054/201404/167226.html.

[3] Wang Zhuli. In the post-epidemic era, how should education be transformed? Expert observation. 2020 ; (04): 002.

[4] Zhang Xiaoli. Analysis and countermeasures of the mental health status of secondary vocational students. Occupation. 2018; (02): 98-99.

[5] Lyu Xidong. (2018) Study on the mental health problems and countermeasures of secondary vocational school students. Master's Thesis, Hebei Normal University, Shijiazhuang. 